\title{
April 2014 Phoenix Critical Care Journal Club: Early Goal-Directed Therapy
}

\author{
The ProCESS investigators. A randomized controlled trial of protocol- \\ based care for early septic shock. New Engl J Med. 2014 epub ahead of \\ print. Available at: http://www.neim.org/doi/full/10.1056/NEJMoa1401602 \\ (accessed 4/24/14).
}

We were fortunate to be joined in our discussion by Dr. Frank LoVecchio, one of the primary investigators of the ProCESS trial, and doctors Robbins, Bajo, Mand and Thomas, as well as our pulmonary critical care fellows.

The ProCESS trial was important for two reasons: first, it showed that early goaldirected therapy (EGDT) does not benefit patient mortality; second, it provides another example of how the evidence-based practice of critical care medicine has often been misguided by invalid evidence. In this aspect, EGDT joins the ranks of tight glucose control, drotrecogin alpha $\left(\right.$ Xigris $\left.^{\circledR}\right)$, Swan Ganz catheterguided resuscitation, corticosteroids, and other interventions in our field that were once part of evidence-based practice, but ultimately found to lack benefit or even be harmful to our patients. That recurrent theme in our literature is the main point of this Journal Club.

The first example of an algorithm for goal-directed therapy (GDT) that we found in the literature was written by Shoemaker in 1975 (1). Shoemaker's proposed algorithm is surprisingly modern-appearing and similar to River's EGDT algorithm. Resuscitation with IVF, blood, vasopressors, and vasodilators (dobutamine was just being developed for commercial use in the 1970s) was aimed at achieving specific goals for blood pressure, central venous pressure, pulmonary artery wedge pressure and hematocrit. Even in the 1960's, it was known that CVP was not a reliable goal for fluid management though, and Shoemaker continued to refine his algorithm, steering away from a CVP-based approach.

Shoemaker published a very influential paper in 1988 (2). This small RCT showed a dramatic mortality benefit of goal-directed therapy aimed at achieving a supranormal cardiac output and oxygen delivery monitored by a Swan Ganz catheter. This approach was based on the theory that resuscitation should not just normalize, but optimize oxygen delivery to tissues, thereby increasing tissue oxygen consumption and preventing organ failure. "Delivery-dependent oxygen consumption" was a theory that made very good sense - and took a decade to disprove.

Delivery-dependent oxygen consumption-based GDT algorithms were subsequently extensively researched and implemented over the next decade. As residents and junior faculty in the late 80 s and early 90 s, we got lots of experience putting in Swans and calculating oxygen delivery to guide resuscitation efforts. But to our great disappointment sequential studies failed to 
confirm any benefit of our efforts. One of the studies we reviewed was an RCT with 762 patients that demonstrated resuscitation focused on a goal of achieving a mixed venous oxygen saturation $\geq 70 \%$ in critically ill patients provided no mortality benefit (3). By 2003, an RCT with nearly 2000 patients that showed no benefit of Swan-based GDT in high-risk surgical patients (4) was the final nail in the coffin of what was beginning to be called "the Cult of the Swan-Ganz" referring to those of us who had trouble giving up our faith in the value of pulmonary artery wedge pressures and oxygen delivery calculations. It was eventually shown that the entire theoretical basis for Swan-based GDT was invalid - that oxygen consumption by tissues was independent of oxygen delivery, except when oxygen delivery got very, very low. Several studies suggested that Swan-Ganz catheters might actually increase patient mortality.

It may have been hard for the fellows, who didn't share this experience, to understand the skepticism that seasoned clinicians had regarding River's "EGDT" trial published in 2001 (5). There was little new about River's version of GDT except the location of care in the emergency room. The goals of EGDT were the same as those that were for the most part tested and disproven decades earlier. There was nothing new therapeutically - IVF, blood, pressors and inotropes had all been part of GDT algorithms since the 1980s. Yet River's trial showed a dramatic reduction of mortality from $46.5 \%$ to $30.5 \%$ ( $p=0.009$, NNT: 6.25) in patients presenting with severe sepsis or septic shock. River's version of GDT became the backbone of evidence-based resuscitation bundles, recommended by the Surviving Sepsis Campaign, the Institute for Healthcare Improvement, and others. By 2008, many non-experimental studies had been published that all seemed to support River's original study results, and greatly expand it's clinical generalizability outside the ER. In fact, the pooled risk reduction when a meta-analysis was performed by Rivers himself was actually even better than in his original study - with a NNT of 5 for every life saved (6). Rivers concluded that these cumulative findings were so incontrovertible, that future efforts should focus on "overcoming logistical, institutional, and professional barriers to implementation". This opinion was widely shared and coordinated efforts were made to incentivize sepsis bundle compliance by physicians.

Before proceeding to the ProCESS trial, recall the setting in which it occurred, because we have been here many times before, and we will be here many times again. As a profession, we were convinced. "Bundle compliance" was considered as failed if even a single aspect of EDGT was not achieved within the proper time frame. Those few who remained skeptical about EGDT had now become "professional barriers" to implementation of one of the most robustappearing examples of evidence-based medicine in our literature. Yet the subsequent negative results of ProCESS ought not to have been a surprise when viewed in light of the history of evidence-based practice in Critical Care. 
The randomized controlled trial of Protocol-based Care for Early Septic Shock (ProCESS) enrolled 1341 patients in 31 emergency rooms across the country. Patients were randomized to three groups: River's-type EGDT, a simplified resuscitation protocol (in which central venous lines were only placed if needed to provide vasopressor infusion, and resuscitation goals were based on blood pressure and pulse), and a non-protocolized "usual care" group. Sixty-day mortality in the groups were $21 \%, 18 \%$ and $19 \%$ respectively - statistically nonsignificant. Not to lose sight of the forest for the trees, we will not further detail the study design of ProCESS, but it enrolled more than five times the number of patients as in River's single-site trial, and there were no major flaws in the design or implementation.

ProCESS ought to teach us this: (again). Evidence-based interventions in critical care that originally appear to reduce mortality are almost always subsequently found to be of no benefit, or to actually harm the patient. This fundamental observation transcends how we normally look at evidence-based medicine. Normally, we take the most recent randomized controlled trial, and abide by the conclusions that we can draw from it. But this approach has repeatedly proven to be wrong. Of all major non-prophylactic treatment interventions in critical care medicine which have been shown to provide a mortality benefit, only ARDSnet low tidal volume ventilation has stood the test of time. Swans, steroids, Xigris, tight glucose control, EGDT, and possibly even post-arrest hypothermia have all fallen. We ought to learn some humility from this in regards to formulating and enforcing rigid protocols for patient care.

More trial evidence is forthcoming. The ongoing Australasian Resuscitation in Sepsis Evaluation (ARISE - but I wonder why it's not just "ARSE"), and Protocolised Management in Sepsis trial (ProMiSe) in the UK will likely shed more light (or more confusion) on the issue. But even if EGDT didn't specifically work after all, the effect of River's study continues to be important. On one hand, we have spent an enormous amount of effort and money trying to rigidly comply with a sepsis resuscitation bundle that is currently disproven to provide any benefit. On the other hand, it's fascinating to note that control group mortality fell from $46 \%$ to $19 \%$ in the twelve years between River's trial and ProCESS. This is an incredible success even if it's only because we paid more attention to sepsis, and not because we complied with a specific resuscitation bundle. We have learned that early diagnosis of sepsis is essential. I hope we will also learn that we can make great strides in critical care without having to all be in lock-step with one particular protocol. There are likely many ways to provide good care for a critically-ill patient. It's important to have a plan for how to do that, but it's unlikely that any single plan is better than all others.

Robert A. Raschke, MD

Banner Good Samaritan Medical Center

Phoenix, AZ 


\section{References}

1. Shoemaker WC. Algorithm for resuscitation: a systematic plan for immediate care of the injured or postoperative patient. Crit Care Med. 1975;3:127-130. [CrossRef] [PubMed]

2. Shoemaker WC, Appel PL, Kram HB, Waxman K et al. Prospective trial of supranormal values of survivors as therapeutic goals in high-risk surgical patients. Chest. 1988;94:1176-86. [CrossRef] [PubMed]

3. Gattinoni L, Brazzi L, Pelosi P, Latini R. et al. A trial of goal-oriented hemodynamic therapy in critically ill patients. New Engl J Med. 1995;333:1025-33. [CrossRef] [PubMed]

4. Sandham JD, Hull RD, Brant RF, Knox L, et al. A randomized controlled trial of the use of pulmonary-artery catheters in high-risk surgical patients. New Engl J Med. 2003;348:5-14. [CrossRef] [PubMed]

5. Rivers E, Nguyen B, Havstad S, Ressler J, Muzzin A, Knoblich B, Peterson E, Tomlanovich M; Early Goal-Directed Therapy Collaborative Group. Early goal-directed therapy in the treatment of severe sepsis and septic shock. New Engl J Med. 2001;345:1368-77. [CrossRef] [PubMed]

6. Rivers E, Coba V, Whitmill M. Early goal-directed therapy in severe sepsis and septic shock: a contemporary review of the literature. Curr Opin Anesthesiol. 2008;21:128-140. [CrossRef] [PubMed]

7. The ProCESS investigators. A randomized controlled trial of protocol-based care for early septic shock. New Engl J Med. 2014 epub ahead of print. Available at: http://www.nejm.org/doi/full/10.1056/NEJMoa1401602 (accessed 4/24/14). 